\title{
Formação profissional em Práticas Integrativas e Complementares: o sentido atribuído por trabalhadores da Atenção Primária à Saúde
}

\author{
Professional Training in Integrative and Complementary Practices: \\ the meanings attributed by Primary Health Care workers
}

Pedro Henrique Brito da Silva (https://orcid.org/0000-0003-3552-0439) ${ }^{1}$

Leylaine Christina Nunes de Barros (https://orcid.org/0000-0003-1599-7571) ${ }^{1}$

Nelson Filice de Barros (https://orcid.org/0000-0002-2389-0056) ${ }^{2}$

Ricardo Antônio Gonçalves Teixeira (https://orcid.org/0000-0002-1603-2088) ${ }^{1}$

Ellen Synthia Fernandes de Oliveira (https://orcid.org/0000-0002-0683-2620) ${ }^{1}$
${ }^{1}$ Programa de PósGraduação em Saúde Coletiva, Universidade Federal de Goiás. Av. Esperança s/n, Chácaras de Recreio Samambaia. 74690900 Goiânia GO Brasil. pedrobryto@gmail.com ${ }^{2}$ Faculdade de Ciências Médicas, Universidade Estadual de Campinas. Campinas SP Brasil.

\begin{abstract}
Objective: To understand the meanings attributed by Primary Health Care workers to the professional training process in Integrative and Complementary Practices. Method: Descriptive, exploratory study with a qualitative approach, carried out with 20 professionals from 14 health units in three municipalities in the Metropolitan Region of Goiânia, state of Goiás, Brazil. Data were collected through semi-structured interviews, transcribed and analyzed using the thematic content analysis. Results: Based on the analysis, the thematic category about training trajectories in Integrative and Complementary Practices emerged. It discusses that the training takes place through training provided by federal and municipal management or professional councils, via distance, semi-presential learning or in-person training. Furthermore, training courses are held at private educational institutions funded by the professionals themselves. Additionally, informal sources of information are used to obtain knowledge (internet, books and magazines). Conclusion: The results show, on the one hand, insufficient and diffuse training, with limited supply and quality and, on the other hand, the need to increase educational strategies to improve the training of health professionals aiming at providing different Integrative and Complementary Practices in the Primary Health Care.
\end{abstract}

Key words Complementary therapies, In-Service training, Continuing education, Primary Health Care
Resumo Oobjetivo deste artigo é compreender os sentidos atribuídos por trabalhadores da Atenção Primária à Saúde ao processo de formação profissional nas Práticas Integrativas e Complementares. Estudo descritivo, exploratório, com abordagem qualitativa, com 20 profissionais, de 14 unidades de saúde de três municípios na Região Metropolitana de Goiânia. Os dados foram coletados com entrevistas semiestruturadas, transcritas e analisadas por meio da Análise de Conteúdo Temática. Da análise, emergiu a categoria temática sobre as trajetórias de formação nas Práticas Integrativas e Complementares. Nela discute-se que a formação se dá por capacitações proporcionadas pela gestão federal, municipal ou conselhos de categoria profissional, via educação à distância, semipresencial ou presencial. Além disso, são realizadas formações em instituições privadas de ensino custeadas pelos próprios profissionais. Também, fontes informais de informações são usadas para obtenção de conhecimento (internet, livros e revistas). Os resultados revelam, por um lado, a formação insuficiente e difusa, com limitação na oferta e na qualidade, por outro, a necessidade de ampliação de estratégias educacionais que melhorem a formação dos profissionais de saúde para a oferta das diferentes Práticas Integrativas e Complementares na Atenção Primária à Saúde.

Palavras-chave Terapias complementares, Capacitação em serviço, Educação continuada, Atenção Primária à Saúde 


\section{Introdução}

Com o Sistema Único de Saúde (SUS), a educação dos trabalhadores passa a ter mais relevância. A Constituição Cidadã, em seu artigo 200, estabelece que "ao Sistema Único de Saúde compete, além de outras atribuições, nos termos da lei, ordenar a formação de recursos humanos na área da

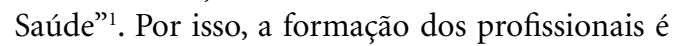
uma atribuição do Ministério da Saúde. A Lei número 8.080, de 19 de setembro de 1990, chamada de Lei Orgânica da Saúde, reforça, no seu Artigo 27, que compete ao SUS "a organização de um sistema de formação de recursos humanos em todos os níveis de ensino, inclusive de pós-graduação, além de elaboração de programas de permanente aperfeiçoamento de pessoal"'. Os apontamentos nas leis federais acima trazem o consenso de que para a consolidação do SUS existe a necessidade de elaboração do conteúdo do ensino na saúde, com definições claras e que promovam a conscientização dos trabalhadores quanto à concretização dos princípios de universalidade, equidade e participação social ${ }^{3}$.

A formação profissional também está expressa na Política Nacional de Práticas Integrativas e Complementares (PNPIC), a qual tem como diretriz o "desenvolvimento de estratégias de qualificação em Práticas Integrativas e Complementares para profissionais no SUS", para assegurar a sua implementação de forma segura e eficaz, levando-se em consideração os paradigmas que as fundamentam, com vistas para o cuidado na construção da integralidade da atenção à saúde à população $0^{5}$.

Entretanto, a formação universitária na saúde possui uma forte tendência em desvalorizar a integralidade, por ensinar os profissionais a reduzir o indivíduo com foco na doença ou nos riscos inerentes a ela. Por outro lado, a integralidade se apresenta como peça-chave para a organização e o alicerce das Práticas Integrativas e Complementares (PIC), como princípio ético e epistemológico. Por conseguinte, o ensino de uma racionalidade médica alternativa e complementar sugere que os estudantes consigam integrar outras visões de mundo ao seu modo de entender o conhecimento e a ciência. De modo que os futuros trabalhadores do SUS sejam menos dualistas e reducionistas do ponto de vista moral, contribuindo para melhorar o relacionamento com os usuários, reduzindo a aplicação de tratamentos invasivos, além de tornar o trabalho em saúde mais resolutivo ${ }^{6-9}$.

Porém, a formação nas PIC pode ser pouco sedutora, diante de um campo da saúde cada vez mais setorializado. A exigência de um profissional formado em uma racionalidade diferente da biomedicina pode ser menos atraente para atender os anseios gerenciais impostos para garantir o "bom" funcionamento dos serviços de saúde ${ }^{10}$. Nesta perspectiva, superar a negatividade da relação entre o trabalho e a educação profissional para tentar reverter o modelo tradicional biomédico, elitizado, mercantilizado, corporativista e voltado principalmente para o atendimento das doenças nos serviços não é tarefa fácil ${ }^{11}$. Nessa circunstância pouco favorável, ainda não sabemos como os profissionais de saúde têm se formado nas PIC para ofertá-las na Atenção Primária à Saúde (APS).

No cenário internacional, $46 \%$ dos médicos suíços, incluindo os da APS, possuem alguma formação em PIC. Os conteúdos abrangendo as PIC estão presentes em mais $80 \%$ das escolas médicas no Canadá, sendo Acupuntura e Homeopatia as mais difundidas. Além disso, são ensinadas em $40 \%$ dos cursos de medicina na União Europeia e em $64 \%$ das faculdades de medicina nos Estados Unidos ${ }^{12,13}$.

Em contrapartida, no Brasil, a formação em PIC é considerada um dos pontos mais críticos para a sua ampliação ${ }^{6,14-18}$. Na graduação em saúde, apenas $26 \%$ dos cursos de enfermagem das universidades públicas oferecem disciplinas que se referem às $\mathrm{PIC}^{19}$. Na medicina, das 272 escolas médicas brasileiras, apenas 57 abordaram PIC em seus currículos nos últimos dez anos. Dessa forma, não houve crescimento significativo no ensino em PIC mesmo diante das necessidades do SUS ${ }^{20}$.

Assim, percebemos que a maioria dos trabalhos envolvendo a formação em PIC tem focado na análise dos currículos universitários. Uma área intrigante e ainda pouco explorada no campo do ensino das PIC são as percepções das pessoas envolvidas no processo formativo ${ }^{21}$. Logo, parte daqui nossa inquietação: como se dá a formação nas PIC na ótica dos profissionais de saúde que as ofertam na APS?

Se as estruturas curriculares dos cursos de saúde impõem limites à formação nas $\mathrm{PIC}^{17}$, justificada pela cultura extremamente biomédica, ao corporativismo profissional e ainda por seguir uma lógica pautada em conteúdos isolados e fragmentados, com enfoque na atenção individual $^{22}$, então, consideramos que os processos formativos dos profissionais de saúde podem ser, majoritariamente, realizados na pós-graduação e no ensino privado.É nesse sentido que este estudo se apresenta e tem por objetivo de com- 
preender os sentidos atribuídos por trabalhadores da Atenção Primária à Saúde ao processo de formação profissional nas Práticas Integrativas e Complementares.

\section{Metodologia}

Trata-se de um estudo descritivo e exploratório, com abordagem qualitativa. Integra o projeto de pesquisa intitulado: "Práticas Integrativas e Complementares nos serviços de Atenção Primária à Saúde - Região Metropolitana de Goiânia", o qual corresponde à proposta da pesquisa finalizada na Região Metropolitana de Campinas pela equipe do Laboratório de Práticas Complementares e Integrativas (LAPACIS http://www.fcm. unicamp.br/fcm/lapacis) da Universidade Estadual de Campinas. Configura-se como a versão estendida do texto publicado nas Atas do Congresso Ibero-americano de Investigação Qualitativa (CIAIQ), realizado em Lisboa - Portugal, em 2019.

Inicialmente, para identificar quais eram as PIC e os profissionais que as ofertavam, verificaram-se os serviços de APS da Região Metropolitana de Goiânia (RMG) no sistema de Cadastro Nacional de Estabelecimentos de Saúde (CNES). Foi possível a identificação de 274 serviços de APS, compreendendo postos e centros da Estratégia da Saúde da Família, Núcleos Ampliados de Saúde da Família (NASF) e Academias da Saúde. Para este estudo, obteve-se a carta de anuência de 17 municípios entre os 20 que compõem a RMG, totalizando 234 serviços de APS.

Realizou-se o contato telefônico com os gerentes das unidades de saúde para checagem dos registros no CNES, sendo excluídos 53 dos 234 serviços, considerando os critérios: reforma do estabelecimento, recusa de participação na entrevista, agenda do gestor local e problemas de telefonia. No que se refere ao segundo semestre de 2017, existiam 23 serviços de APS, nos quais 29 profissionais ofertavam alguma PIC, em cinco cidades na RMG.

Dos 29 identificados, sete profissionais não participaram do estudo: um se recusou a participar; três não foram contatados e três haviam encerrado a oferta das PIC. O critério de exclusão era em relação àqueles profissionais de saúde que, por motivo de falta, férias ou licença de qualquer natureza, não estavam nos serviços de APS na RMG, no período de coleta de dados que compreendeu os meses de janeiro a agosto de 2018. Assim, dois profissionais foram excluídos, pois ambos estavam de licença-prêmio. Por fim, o estudo contou com a participação de 20 profissionais, de 14 serviços de APS, de três municípios da RMG.

As entrevistas foram previamente agendadas com o profissional, por contato telefônico. Nessa primeira abordagem foram feitas a apresentação do investigador e da pesquisa, dos seus objetivos e da sua relevância. Em seguida, foi feito o convite para a participação e a marcação da entrevista, em dia e horário segundo a disponibilidade de cada um dos entrevistados.

Foram realizadas entrevistas direcionadas por um roteiro previamente elaborado que permitiu realizar questionamentos básicos e abordar assuntos pertinentes à investigação, tais como: "conte-me um pouco da sua formação profissional (faculdade, curso profissionalizante, especialização, etc.); O que você fez para se capacitar na área das PIC (cursos, especialização, seminários, etc.)?”.

No momento da entrevista presencial e individualizada, realizou-se uma breve contextualização e esclarecimentos de qualquer dúvida sobre a pesquisa. Em seguida, foi entregue o Termo de Consentimento Livre e Esclarecido a ser assinado pelo entrevistado, resguardando a sua identidade e a confidencialidade das informações prestadas. Depois disso, a entrevista foi realizada com os participantes tendo duração, em média, de 45 minutos, em ambiente reservado e considerado mais conveniente ao profissional (no local/ área onde ocorre a PIC ou consultório do serviço de APS), pois o entrevistado precisa se sentir confortável no espaço onde ocorre a entrevista ${ }^{23}$. As entrevistas foram gravadas em áudio e transcritas na íntegra.

Empreendeu-se a análise de conteúdo na modalidade temática, guiando-se pela trajetória proposta por Bardin ${ }^{24}$, que consiste no conjunto de técnicas de análise das enunciações visando obter, por procedimentos sistemáticos e objetivos, a inferência sobre o que foi tematizado nas mensagens. A organização dos dados foi dividida em três etapas: 1) pré-análise; 2) exploração do material e 3) interpretação dos resultados. A pré-análise consistiu na leitura flutuante do material, para identificar os sentidos atribuídos pelos participantes. Para a exploração do material foram realizadas leituras detalhadas dos sentidos identificados, com o objetivo de agrupar as ideias convergentes/divergentes que emergiram com maior relevância.

Dessa etapa emergiram os seguintes núcleos de sentido: capacitação ofertada pelo Ministério 
e/ou Secretaria Municipal de Saúde; formação no setor privado; oferta de PIC sem educação formal; carência de formação nas PIC ofertada pelo setor público; cursos com carga horária limitada; falta de apoio da gestão para a implementação da PIC após a capacitação; formação nas PIC relacionada à integralidade. Para a interpretação dos resultados, a categoria de análise, "as trajetórias de formação nas PIC", referente aos núcleos de sentido foi discutida. Para a organização e a sistematização dos dados foi utilizado um programa de apoio a pesquisas com dados não numéricos e não estruturados ${ }^{25}$. Os discursos foram codificados com a letra "P", acrescida do número atribuído a cada participante da pesquisa. O projeto foi aprovado pelo Comitê de Ética em Pesquisa.

\section{Resultados}

Participaram do estudo 20 trabalhadores do SUS de formações profissionais diversas, sendo seis enfermeiras, dois psicólogos, duas fisioterapeutas, duas assistentes sociais, duas nutricionistas, dois farmacêuticos, uma técnica de enfermagem, uma agente comunitária de saúde, uma cirurgiã-dentista e uma terapeuta ocupacional. A PIC mais frequente foi a Auriculoterapia, ofertada por nove profissionais, seguida, respectivamente, pelo Reiki, Terapia Comunitária, Fitoterapia, Arteterapia, Shantala e Acupuntura.

Dos entrevistados, 18 possuíam curso superior completo, sendo que 14 deles contavam com pós-graduação Lato Sensu e dois com mestrado Stricto Sensu. Entre estes trabalhadores de saúde, 15 eram do sexo feminino, profissionalmente experientes, com uma maioria significativa (12) com mais de dez anos de formados. Do total, sete trabalhadores estavam na faixa etária entre $31 \mathrm{e}$ 40 anos e 14 tinham vínculo empregatício estável. Entre tais profissionais, oito autorreferiramse brancos, 10 eram casados e sete se declaravam católicos.

De modo geral, foram distintas e ao mesmo tempo convergentes as trajetórias que conduziram os profissionais para a busca de formação nas PIC. Esta constatação pode ser evidenciada na exposição dos núcleos de sentidos que emergiram das narrativas dos profissionais, explicitando como esses profissionais de saúde buscaram se formar em uma nova prática terapêutica e os sentidos atribuídos por eles à formação nas PIC.

Observou-se que a formação ocorre por capacitações de curta duração, de modo presencial ou à distância, oferecidas pelo Ministério da Saúde, Secretarias Municipais de Saúde e conselhos de categorias profissionais, com destaque para a enfermagem. Havia também aqueles que se formaram no ensino privado, em que o financiamento foi custeado pelo próprio trabalhador. $\mathrm{E}$ que a oferta na APS é implementada por profissionais que não detém educação formal na PIC.

Os profissionais que oferecem Auriculoterapia percorrem diferentes itinerários para aprender essa prática terapêutica pertencente à Medicina Tradicional Chinesa. Uma das capacitações realizada por duas profissionais, uma farmacêutica e uma nutricionista, consiste:

um curso fornecido mesmo lá pelo Ministério da Saúde. Um curso on-line, com cinco ou seis módulos. Não Tinha nem tutor, nem nada. A gente entrava, tinha o material para você imprimir, também uns vídeos. Esse curso foi oferecido em parceria com a Universidade de Santa Catarina (P2).

o último módulo você tinha que ir presencialmente em uma aula e aí cada pessoa que fazia inscrição escolhia em qual cidade que queria fazer essa aula prática. Fiz essa aula prática em meio período. Não ficavam focando muito em ensinar a parte teórica, não. Ensinavam mesmo a prática (P7).

Outro modo de capacitação em Auriculoterapia foi através de um curso disponibilizado pela Secretaria Municipal de Saúde de Goiânia. O farmacêutico que fez essa formação explica que:

o curso de auriculoterapia nós fizemos nas sextas-feiras, foi agora no início de janeiro, foram quatro sextas-feiras. [Realizado em] um período, o período da tarde. Faz parte do curso, o atendimento de 24 usuários, que a gente vai ter que relatar os atendimentos e estar enviando também para tutora nossa do curso para poder estar completando a carga horária, de mais ou menos 40 horas (P9).

Além da Secretaria Municipal de Saúde de Goiânia e do Ministério da Saúde, o Conselho Regional de Enfermagem também desenvolveu capacitação em Auriculoterapia. O curso, segundo a enfermeira participante,

foi por três noites, das seis às 10, carga horária de 12 horas. E nesse curso, ela [a instrutora] começou com a parte teórica, falou de como veio a origem, explicou tudo. Foram dois dias de teoria e um dia de prática. Na prática, ela mostrou para gente, definiu direitinho como funciona, o que é a auriculoterapia que é uma medicina terapêutica chinesa, explicou para gente como atua, a finalidade e nós praticamos entre uma e outra (P14).

Outros três profissionais obtiveram a formação em Auriculoterapia no ensino privado. Duas delas, em um módulo realizado em sua especia- 
lização em Acupuntura. A terceira, custeou a sua própria capacitação, em curso voltado para aplicação da Auriculoterapia, tendo uma carga horária de 20 horas, de modo presencial, durante um fim de semana.

No que concerne à Fitoterapia, o Hospital de Medicina Alternativa de Goiânia, em 2016, disponibilizou um curso de capacitação realizado pelos dois profissionais que a utilizam na APS na RMG. Não havia vínculo com as gestões municipal, estadual e federal. Compreendia em um encontro semanal no período da manhã, durante seis meses, sendo realizado durante o horário de trabalho.

As profissionais que desenvolvem o Reiki na APS na RMG explanam que:

Nós fizemos o curso por conta própria, a gente pagou [...] o Reiki, ele tem vários níveis, eu só fiz o um, e aí ele durou o quê? Umas 20 horas o curso (P3).

Não foi ofertado pela secretaria, foi fora. O curso ele teve a duração de 40 horas (P17).

Foi por conta própria. $O$ [curso de] Reiki foi nos finais de semanas. Que vai dar 20 horas (P18).

A formação das enfermeiras que ofertam Acupuntura também ocorreu em escolas privadas. As profissionais narram que os cursos são especializações Lato Sensu com duração de um ano e oito meses a dois anos:

O curso [de acupuntura] tem duração de 24 meses. Estou no quinto módulo. É presencial, aos fins de semana. Esse curso não foi oferecido pela Secretaria de Saúde. Fui eu que busquei esse curso mesmo (P11).

O curso é particular, eu pago particular. O curso é presencial, aula uma vez no mês e depois de seis meses de curso a gente faz [a prática] no ambulatório. O ambulatório é um espaço que você atende os pacientes, então as pessoas vão lá e você atende, você pratica o que você aprendeu (P12).

[O curso] foi da minha parte mesmo. Eu que busquei. Foi um ano e oito meses, um ano e meio com aulas teóricas e práticas e três meses só de prática (P16).

Uma outra formação por especialização foi a Terapia Comunitária, o qual só foi possível ser realizada pelo entrevistado pela parceria entre a Pastoral da Criança e do Adolescente conveniada com a Universidade Federal do Ceará, em Brasília. O profissional ressalta que o curso geralmente, pegava sextas, sábados e domingos intensivos. O total do curso era de 360 horas. Era dividido entre os encontros presenciais e os estágios. Durante o curso, uma parte da carga horária, era aplicação das técnicas nos nossos lugares de atuação (P10).
Os demais profissionais da Terapia Comunitária, juntamente com os trabalhadores que ofertam Arteterapia e Shantala, formam o grupo que não possui qualquer educação formal nas PIC. Diante disso, procuraram outras fontes para aquisição de conhecimento:

Comprei o livro, comecei a estudar. Então essa foi a forma como eu me formei, vamos assim dizer (P5).

Desde que eu me entendo por gente eu via minha mãe fazendo e aprendi com ela (P6).

Era assim, compramos revistas, aprendemos por revistas (P15).

De academia assim, não. Foi só na coragem e observando vídeos (P16).

Por outro lado, os profissionais das formações acadêmicas mais tecnicistas, como é o caso da Odontologia, o curso de Auriculoterapia despertou para um cuidado mais integral, que produz muita desconstrução daquele cuidado só com medicamento, centrada no biológico. Tem uma desconstrução para gente entender o todo (P11).

Constatou-se que os profissionais que ofertam as PIC possuem um tempo considerável de conclusão de sua formação acadêmica e de experiência na APS na RMG. Contudo, para uma entrevistada, que há mais de 10 anos completou a sua graduação, existe uma falta de alternativas para a capacitação em PIC:

Eu não tive a possibilidade, o privilégio de fazer através da secretaria sem pagar nada. Eu acho que deveria de ser, a gente teria que ter isso dentro do SUS (P8).

À vista disso, a inexistência de estratégias educacionais deixa os profissionais receosos em executar a prática. Esse sentimento é compartilhado pelos trabalhadores, principalmente, aqueles que não possuem uma educação formal na PIC. Uma das terapeutas comunitárias revela que não é uma coisa que você sente segura, totalmente segura. Porque acho que precisa dessa formação. Sim, faz falta (P13).

Os participantes narram limitações nas capacitações oferecidas pelo Ministério da Saúde e/ ou Secretaria Municipal de Saúde. Consideram a carga horária reduzida como um dos principais pontos negativos na formação e/ou capacitação:

A carga horária era de 20 horas, presencial, em uma escola aqui em Goiânia, mesmo. Eu acho vinte horas muito pouco para entender a Medicina Tradicional Chinesa (P11).

Acho que faltou. Foi muito rápido. $O$ curso foi durante três meses, uma vez na semana, só. As aulas eram mais teóricas do que práticas. E, assim, achei que faltou muito (P1). 
Uma das trabalhadoras, relata Você acredita que depois de assinar o documento para fazer o curso, queriam voltar atrás? Não oferece nenhum curso, quando oferece, ficou assim: Onde está a autorização? O secretário autorizou? Não era para ser autorizado. Penso que é pela ausência [do trabalho] (P1). Essa falta de estímulo a realizar cursos, supervisões e reciclagens foi observada nas falas dos entrevistados, sendo que essa dificuldade é ainda maior para aqueles trabalhadores que possuem vínculo empregatício frágil.

Somado a isso, a oferta das capacitações não tem sido acompanhada de recursos financeiros para a sua implementação nos serviços de saúde, A coordenadora mesmo que está promovendo esse curso de Auriculoterapia que está ocorrendo, iria conversar com as pessoas. Para as pessoas [profissionais] investirem nas placas [das agulhas para aplicação da Auriculoterapia], só (P4). O apoio e a regulamentação das práticas não são identificados na prática, Na teoria a gestão central apoia, tanto é que fez o curso e tudo o mais. Agora, apoio prático mesmo, questão de insumos etc., isso aí até hoje não aconteceu (P9).

\section{Discussão}

Ainda que o Ministério da Saúde brasileiro tenha atendido ao chamado da Organização Mundial da Saúde ${ }^{4}$ e de várias categorias profissionais do campo da saúde no Brasil com a criação da PNPIC, a implantação e a implementação das PIC no SUS precisa ser incrementada, principalmente em relação à formação dos profissionais que as ofertam na APS. Os núcleos de sentido que emergiram das narrativas dos profissionais participantes deste estudo são transversalmente entrecortados pela categoria de análise relacionada à trajetória de formação nas PIC.

Neste estudo, evidenciamos que alguns profissionais recorrem ao setor privado para se formar nas PIC. Isso concorda com achados anteriores na literatura ${ }^{10,14,21,26,27}$. A formação em PIC no país tem se concentrado no setor privado, por meio de cursos de pós-graduação lato sensu $u^{10,14,28}$. Esse tipo de formação pode ser um problema, uma vez que ele tende a replicar modelos educacionais voltados para a realidade da prática privada, que não atendem ao contexto das PIC na APS e no SUS ${ }^{16,28}$.

De outro modo, encontramos que os processos de formação e capacitação dos profissionais que estavam ofertando PIC na RMG se dá mediante curso oferecido pela Secretaria Municipal de Saúde de Goiânia. Esse tipo de formação é observado em outras realidades do país ${ }^{29,30}$. Esse tipo de formação, mesmo que tímido e introdutório, pode desempenhar um importante papel frente ao desconhecimento significativo e do interesse dos profissionais em atividade na APS com relação às PIC $^{16}$.

Nesse seguimento, o Ministério da Saúde também contribuiu, mesmo que de maneira discreta, para a formação dos nossos entrevistados. Esse curso semipresencial de Auriculoterapia de 80 horas, capacitou mais de 4 mil profissionais, no período entre 2016 e $2017^{31}$. Essa iniciativa do governo federal ainda não foi extensivamente explorada, cabendo a realização de estudos na área ${ }^{16}$. Os resultados desses trabalhos futuros podem indicar que esse tipo de formação possibilite a expansão das PIC na APS.

Nosso estudo também encontrou que outras fontes de conhecimento foram usadas para obtenção de informações (internet, contato com outras pessoas, livros, revistas). Tal fato pode se tornar preocupante quando observamos, através dos relatos, que as informações provêm por meios eletrônicos e pesquisa pessoal, revelando um caráter informal para uma área importante para a saúde humana. Esses mecanismos podem ser um compensador da falta de recursos acadêmicos formadores de profissionais para atuar com as demandas dos serviços de saúde, apesar das iniciativas existentes nos últimos anos ${ }^{32-34}$.

Nossos achados apontam que a formação e a capacitação nas PIC favorecem uma visão mais integral no trabalho na saúde. Essa evidência está alinhada com o resultado de outro estudo ${ }^{35}$. A integralidade, reconhecida como imagem-objetivo dentre os princípios constitucionais do SUS, tem se destacado por apontar o retorno das dimensões subjetivas e sociais como constitutivas do saber-fazer em saúde ${ }^{36}$. Sendo assim, a educação nas PIC enriquece a prática profissional dos entrevistados, tornando-os mais empáticos e com mais interesse pelos usuários.

Os nossos entrevistados narram a falta de opções educacionais em PIC no SUS, tendo de arcar com os custos da formação. Além disso, essa ausência deixa o profissional inseguro para oferecer a PIC no trabalho. Esses resultados robustecem ainda mais o conceito de que o preparo do profissional de saúde atualmente não tem acompanhado a oferta das PIC nas unidades de saúde, o que pode aumentar a fragilidade do seu atendimento $^{37-40}$.

Os nossos dados revelam que as capacitações nas PIC são apresentadas de forma precária, o 
que pode limitar a compreensão desses profissionais. Esse achado está alinhado com os resultados de outra pesquisa ${ }^{41}$. Os profissionais consideram a formação e a sua prática complexa, fazendo críticas aos cursos de curta duração. Essa complexidade requer um entendimento tal, que em um curto período pode resultar em formações deficientes para a execução de uma boa prática.

As várias racionalidades médicas coexistentes são oriundas de diversas culturas distintas, com conceitos diferentes de saúde e adoecimento. Logo, oferecer formação nas PIC de maneira simplista ainda pode ocasionar o risco de submissão de um paradigma a outro, com prejuízos em suas contribuições ${ }^{27}$. Por isso, consideramos que a formação dos trabalhadores da saúde deve ser mais bem fundamentada para intensificar os pontos de aproximação e intersecção da biomedicina com as PIC, trazendo as possibilidades de interação, complementaridade e colaboração na formação de profissionais mais sensíveis com o cuidado ampliado e atenção integral à saúde ${ }^{42,43}$.

Assim, para garantir que os profissionais estejam alinhados com a lógica da integralidade é necessário investimento para além das suas graduações básicas, sendo fundamental o incremento de competências colaborativas para a superação do trabalho individual e hierarquizado no interior dos serviços. Essas mudanças são difíceis de serem encaradas, pois os profissionais foram formados na biomedicina que privilegia o trabalho individual e especializado. Formar-se em outra racionalidade que difere da "normalidade", configura uma nova lógica no agir desses profissionais, ao mesmo tempo, que produz constrangimentos pela motivação em fugir do imobilismo que o sistema de saúde tem imposto sobre os trabalhadores ${ }^{44}$.

Nessa sequência, nosso estudo descobriu que a ausência do trabalho gera conflito entre o profissional e a gestão, tornando um elemento dificultador para a formação nas PIC. A organização da assistência em saúde tem alienado o trabalhador, ocorrendo um processo de reificação da sua essência, isto é, um estranhamento da sua própria condição humana, com repercussão nas suas relações sociais. Aprender PIC nesse ambiente pouco favorável pode tornar-se uma ousadia e momentos de fissura nos processos instituídos ${ }^{3}$.

Isso fica mais evidente quando os profissionais relatam que, mesmo com o oferecimento da capacitação, não existe o fornecimento de materiais para a implementação da prática. Essa dificuldade enfrentada pelo trabalhador alternativo da rede pública de saúde é facilmente encontrada na literatura ${ }^{45-47}$. Sozinha, a formação em PIC, seja virtual, presencial ou semipresencial, não garante a sua implementação. A capacitação deve estar acompanhada de condições propícias para o desenvolvimento da prática. Com isso, evidenciamos que a execução das PIC é desenvolvida sem apoio do gestor e sem institucionalização significativa da oferta ${ }^{16}$.

Dessa forma, nossos métodos deveriam incluir os sentidos dos gerentes dos serviços de saúde sobre a formação nas PIC, já que eles também são um importante ator na formação em saúde, indicando uma das limitações deste estudo. Apontamos como outra limitação o período de coleta de dados que poderia ser mais abrangente, uma vez que as capacitações em PIC estavam sendo oferecidas naquele momento na RMG.

\section{Conclusão}

Nosso estudo nos levou à conclusão de que o processo de formação nas PIC dos profissionais para oferecê-las na APS se dá por intermédio de capacitações proporcionadas pela gestão federal, municipal ou conselho de categoria profissional. Também, descobrimos que os trabalhadores de saúde financiam a sua própria formação no ensino privado, pois não encontram capacitação em determinadas PIC no setor público. Neste estudo, observamos ainda que a obtenção de conhecimento em torno das PIC pode se dar de modo informal, recorrendo às fontes midiáticas, o que reforça a falta de elaboração de iniciativas de educação nas PIC para qualificação dos profissionais no SUS. Portanto, os nossos dados demonstram que a formação não tem se restringido às instituições privadas como havíamos considerado inicialmente.

Em conjunto, esses resultados sugerem que os processos formativos em PIC são heterogêneos, deficientes e limitados. As descobertas deste estudo indicam a carência de ordenação de formação de recursos humanos e desenvolvimento de estratégias de qualificação nas PIC. Em geral, esses resultados evidenciam um relativo despreparo técnico e político dos profissionais de saúde para a implementação das PIC na APS. Porém, mesmo com as formações de caráter introdutório, os nossos achados mostram a sua capacidade em estimular mudanças no padrão biologizante $\mathrm{e}$ medicalizante do cuidado em saúde.

Os nossos resultados indicam a necessidade de extensão das estratégias educacionais que abrangem a totalidade das práticas terapêuticas 
contempladas na PNPIC. Nesse sentido, este estudo avançou de alguma maneira no aprimoramento de nossa compreensão sobre a formação dos profissionais de saúde nas PIC, pois sugere algumas ações a serem observadas quando a formação for oferecida no SUS, como: capacitações com carga horária maior; incentivo e apoio da gerência dos serviços de saúde para a realização da formação; e disponibilidade de insumos para a implementação da prática.
Por consequência, esperamos encorajar a discussão na academia e na gestão para a importância da formação nas PIC para a sua inserção na APS. Ter profissionais de saúde aptos para desempenhar essas práticas é um modo para que elas sejam mais valorizadas e estejam mais disponíveis para toda a população, trazendo melhorias para os usuários e trabalhadores do SUS.

\section{Colaboradores}

PHB Silva, LCN Barros, NF Barros, RAG Teixeira e ESF Oliveira contribuíram substancialmente na concepção e no planejamento do estudo; na obtenção, na análise e interpretação dos dados e na redação e revisão crítica e aprovaram a versão final a ser publicada. 


\section{Referências}

1. Brasil. Lei 8.080, de 19 de setembro de 1990. Dispõe sobre as condições para a promoção, proteção e recuperação da saúde, a organização e o funcionamento dos serviços correspondentes e dá outras providências. Diário Oficial da União 1990; 20 set.

2. Brasil. Constituição Federal da República do Brasil. Diário Oficial da União 1988; 5 out.

3. Lemos CLS. A concepção de educação na Política Nacional de Educação Permanente em Saúde [tese]. Goiânia: Universidade Federal de Goiás; 2010.

4. Brasil. Ministério da Saúde (MS). Secretaria de Atenção à Saúde. Departamento de Atenção Básica. Política Nacional de Práticas Integrativas e Complementares no SUS. Brasília: MS; 2006.

5. Deus RL. Trabalhadores da Atenção Primária à Saúde e Práticas Integrativas e Complementares - do uso à indicação [dissertação]. Juiz de Fora: Universidade Federal de Juiz de Fora; 2016.

6. Barros NF, Siegel P, Otani MAP. O Ensino das Práticas Integrativas e Complementares: experiências e percepções. São Paulo: Hucitec; 2011.

7. Broom A, Adams J. Uma sociologia da educação em saúde integrativa. In: Nascimento MC, Nogueira MI, organizadores. Intercâmbio solidário de saberes em saúde: Racionalidades Médicas e Práticas Integrativas e Complementares. São Paulo: Hucitec; 2013. p. 139 153.

8. Haramati A, Adler SR, Wiles M, Sierpina VS, Kreizer MJ. Innovation and Collaboration: The First International Congress for Educators in Complementary and Integrative Medicine. Explore 2013; 9(2):118-120.

9. Schiff E, Attias S, Hen H, Kreindler G, Arnon Z, Sroka $\mathrm{G}$, Ben-Arye E. Integrating a complementary medicine service within a general surgery department: from contemplation to practice. J Altern Complement Med 2012; 18(3):300-305.

10. Habimorad PHL, Catarucci FM, Bruno VHT, Silva IB Fernandes VC, Demarzo MMP, Spagnuolo RS, Patricio KP. Potencialidades e fragilidades de implantação da Política Nacional de Práticas Integrativas e Complementares. Cien Saude Colet 2020; 25(2):395-405

11. Lemos CLS. Educação Permanente em Saúde no Brasil: educação ou gerenciamento permanente? Cien Saude Colet 2016; 21(3):913-922.

12. World Health Organization (WHO). WHO traditional medicine strategy: 2014-2023. Geneva: WHO; 2013.

13. Teixeira MZ, Lin CA, Martins MA. O Ensino de Práticas Não-Convencionais em Saúde nas Faculdades de Medicina: Panorama Mundial e Perspectivas Brasileiras. Rev Bras Educ Med 2004; 28(1):51-60.

14. Azevedo E, Pelicioni MCF. Práticas integrativas e complementares de desafios para a educação. Trab Educ Saúde 2012; 9(3):361-378.

15. Sousa IMC, Bodstein RC, Tesser CD, Santos FAS, Hortale VA. Cad Saude Publica 2012; 28(11):2143-2154.

16. Tesser CD, Sousa IMC, Nascimento MC. Práticas Integrativas e Complementares na Atenção Primária à Saúde brasileira. Saúde Debate 2018; 42(n. esp. 1):174188.

17. Dalmolin IS, Heidmann ITSB. Práticas integrativas e complementares e a interface com a promoção da Saúde: revisão integrativa. Ciênc Cuid Saúde 2017; 16(3):1-8.
18. Dalmolin IS, Heidemann ITSB, Freitag VL. Práticas integrativas e complementares no Sistema Único de Saúde: desvelando potências e limites. Rev Esc Enferm USP 2019; 53:e03506.

19. Salles LF, Homo RFB, Silva MJP. Situação do ensino das práticas integrativas e complementares nos cursos de graduação em enfermagem, fisioterapia e medicina. Cogitare Enferm 2014; 19(4):741-746.

20. Albuquerque LVC, Silva ABG, Correia ICM, Maia LROG, Bessa MC, Bessa OAAC. Complementary and Alternative Medicine Teaching: Evaluation of the Teaching-Learning Process of Integrative Practices in Brazilian Medical Schools. Rev Bras Educ Med 2019; 43(4):109-116.

21. Nascimento MC, Romano VF, Chazan ACS, Quaresma $\mathrm{CH}$. Formação em práticas integrativas e complementares em saúde: desafios para as universidades públicas. Trab Educ Saúde 2018; 16(2):751-772.

22. Freitag VL, Dalmolin IS, Badke MR, Andrade AD. Benefícios do Reiki em população idosa com dor crônica. Texto Contexto Enferm 2014; 23(4):1032-1040.

23. Muylaert CJ, Sarubbi Júnior V, Gallo PR, Rolim Neto ML, Reis AOA. Entrevistas narrativas: um importante recurso em pesquisa qualitativa. Rev Esc Enferm USP 2014; 48(n. esp. 2):193-199.

24. Bardin L. Análise de Conteúdo. São Paulo: Edições 70; 2016.

25. Mozzato AR, Grzybovski D. Análise de conteúdo como técnica de análise de dados qualitativos no campo da administração: potencial e desafios. RAC 2011; 15(4):731-747

26. Tesser CD. Práticas Integrativas e Complementares e racionalidades médicas no SUS e na atenção primária à Saúde: possibilidades estratégicas de expansão. $J$ Manag Prim Health Care 2017; 8(2):216-232.

27. Nascimento MVN, Oliveira IF. Práticas integrativas e complementares grupais e diálogo com a educação popular. Psicol Pesq 2017; 11(2):89-97.

28. Teixeira MZ, Lin CA. Educação médica em terapêuticas não convencionais. Rev Med (São Paulo) 2013; 92(4):224-235.

29. Moré AOO, Tesser CD, Min LS. Integrating acupuncture into primary health care: the experience of an educational model implemented within the Brazilian Unified Health System in Florianópolis. Acupunct Med 2016; 34(6):476-481.

30. Prefeitura de São Paulo. Secretarias. Saúde. Atenção Básica. Medicinas Tradicionais. [acessado 2018 Jan 26]. Disponível em: http://www.prefeitura.sp.gov.br/

31. Botelho LJ. Formação em Auriculoterapia para profissionais de saúde da Atenção Básica [relatório final]. Florianópolis: UFSC; 2017.

32. Cruz PLB, Sampaio SF. O uso de práticas integrativas e complementares por uma equipe de Saúde da família e a população. Rev APS 2012; 15(4):486-495.

33. Gonçalves RP, Antunes HM, Teixeira JBP, Ludmila OC, Barros PR. Profissionais da área da Saúde pública: atitudes, conhecimentos e experiências em relação a práticas médicas não convencionais. Rev APS 2008; 11:398-405.

34. Chehuen Neto JA, Sirimarco MT, Duarte Neto JA, Valle DA, Martins JSC, Cândido TC. Uso e compreensão da medicina complementar pela população de Juiz de Fora. HU Rev 2010; 36(4):266-326. 
35. Shuval JT, Gross R, Ashkenazi Y, Schachter L. Integrating CAM and Biomedicine in Primary Care Settings: Physicians' Perspectives on Boundaries and Boundary Work. Qual Health Res 2012; 22(10):1317-1329.

36. Wenceslau LD, Rohr F, Tesser CD. Contribuições da Medicina Antroposófica à integralidade na educação médica: uma aproximação hermenêutica. Interface (Botucatu) 2014; 18(48):127-138.

37. Oliveira SGD, Moura FRR, Demarco FF, Nascente PS, Del Pino FAB, Lund RG. An ethnomedicinal survey on phytotherapy with professionals and patients from Basic Care Units in the Brazilian Unified Health System. J Ethnopharmacol 2012; 140(2):428-437.

38. Sampaio LA, Oliveira DRD, Kerntopf MR, Brito Júnior FEDB, Menezes IRAD. Percepção dos enfermeiros da estratégia Saúde da família sobre o uso da fitoterapia. Rev Min Enferm 2013; 17(1):76-84.

39. Spadacio C, Castellanos MEP, Barros NF, Alegre SM, Tovey P, Broom A. Medicinas Alternativas e Complementares: uma metassíntese. Cad Saude Publica 2010; 26(1):7-13.

40. Thiago SCS, Tesser CD. Percepção de médicos e enfermeiros da Estratégia de Saúde da Família sobre terapias complementares. Rev Saude Publica 2011; 45(2):249-257.

41. Nunes MF, Junges JR, Gonçalves TR, Motta MA. A acupuntura vai além da agulha: trajetórias de formação e atuação de acupunturistas. Saúde Soc 2017; 26(1):300-311.

42. Nascimento MC, Barros NF, Nogueira MI, Luz MT. A categoria racionalidade médica e uma nova epistemologia em Saúde. Cien Saude Colet 2013; 18(12):35953604.
43. Tesser CD. Práticas Complementares, Racionalidades Médicas e promoção da Saúde: contribuições pouco exploradas. Cad Saude Publica 2009; 25(8):1732-1742.

44. Oliveira MCS. As (in)visibilidades do Lian Gong na Atenção Primária em Saúde [dissertação]. Campinas: Universidade Estadual de Campinas; 2018.

45. Ischkanian PC, Pelicioni MCF. Desafios das práticas integrativas e complementares no SUS visando a Promoção da Saúde. J Human Growth Dev 2012; 22(1):233-238.

46. Nagai SC, Queiroz MS. Medicina complementar e alternativa na rede básica de serviços de Saúde: uma aproximação qualitativa. Cien Saude Colet 2011; 16(3):1793-1800.

47. Galhardi WMP, Barros NF, Leite-Mor ACMB. A homeopatia na rede pública do Estado de São Paulo: facilitadores e dificultadores. Rev Bras Med Fam Comunidade 2012; 7(22):35-43.

Artigo apresentado em 07/04/2020

Aprovado em 26/05/2020

Versão final apresentada em 28/05/2020

Editores chefes: Maria Cecília de Souza Minayo, Romeu Gomes, Antônio Augusto Moura da Silva 